\title{
Structural changes in the Polish higher education system (1990-2010): a synthetic view
}

\author{
Marek Kwiek* \\ Center for Public Policy Studies, UNESCO Chair in Institutional Research and Higher Education \\ Policy, University of Poznan, Poznan, Poland
}

(Received 1 March 2014; accepted 15 March 2014)

\begin{abstract}
The paper locates the past two decades of changes in Polish universities in a comparative European context. It shows a wider transition: from an expanding, privatized and disciplinarily divided university of the 1990s to a publicly funded, increasingly contracting and stratified university of the 2000s (and beyond). The gradual political and economic integration of Poland with the European Union has been accompanied by the gradual integration of the Polish higher education system with Western European systems. The paper argues that the major emergent parameter of higher education policy is demographics and that the remonopolization of the system by the tax-based public sector and the gradual decline of the private sector are transforming the system beyond recognition. Processes of 'de-privatization' or 'republicization' are gradually replacing recent processes of 'privatization'. Powerful systemic changes in university governance and funding modes are bound to shatter the relative stability of the academic profession. After two decades of being fundamentally different due to the communist legacy (i.e. being 'post-communist'), selected Polish universities, owing to accelerating processes of academic stratification linked to the 2009-2012 wave of reforms, have a chance to become fully blown elements of a European knowledge production landscape, with increasingly similar governance and funding regimes and the similarly research-involved academic profession.
\end{abstract}

Keywords: Polish higher education; privatization; demographics; public-private; system contraction

\section{Introduction}

The paper synthesizes major changes in Polish higher education in the last two decades. It focuses on changes in governance, management, funding and the academic profession and links them to major social, economic, political and demographic drivers. In particular, a recent wave of reforms (2009-2012) is analysed, with its potentially deep impact on further structural transformations. The paper discusses the following four themes: (1) the disciplinarily divided university (with divergent academic rules, norms and codes of behaviour in hard and soft academic fields and the ensuing deinstitutionalization of the research mission of the university in soft fields), (2) the privatized expanding university and the publicly funded contracting university (with initially massive external and internal privatization, and the currently changing public-private dynamics under declining demographics), (3) the stratified university (with the increasing differentiation of

\footnotetext{
*Email: kwiekm@amu.edu.pl
} 
institutional 'haves' and 'have-nots' in research funding, following the emergence of a new competitive and individualized research funding regime) and (4) the Ivory Tower university (with an unprecedented low, from a European comparative perspective, level of its connectedness to the outside world). The paper explores the extent of changes in each of the themes and locates them briefly in comparative European contexts. The selection of themes was guided by their relevance to past and ongoing structural changes, especially to recent reforms: they are instrumental in capturing a wider transition from an expanding, privatized and disciplinarily divided university of the 1990 s to a publicly funded, contracting and stratified university, ever more socially and economically relevant, of the 2000s and beyond.

Polish higher education has changed fundamentally since 1989, both quantitatively (higher participation rates, numbers of students, faculty and institutions) and qualitatively (regained institutional autonomy and academic freedom, shared governance, emergent public-private duality, new competitive research funding regimes and fee regimes). The scope of changes and their speed are not easy to comprehend outside of the context of the overall post-communist transition to an open, market-driven economy, fully integrated with European Union's (EU) economies. The gradual political, economic and social integration of Poland with the EU has been accompanied by the deepened, gradual integration with Western European higher education and research systems, already involved in the deepened European integration processes (Maassen and Olsen 2007; Kwiek and Maassen 2012). Polish higher education became a dual (public-private) highly differentiated, strongly marketized and hugely expanded system, with all ensuing consequences of fast changes for both institutions and the academic profession. Since 1989 , the system has witnessed the phenomenal rise in the number of public and private institutions, the rise and fall in the number of students (from 0.40 million in 1989 up to 1.95 million in 2006 and down to 1.67 million in 2012), the rise in the number of doctoral students (from about 2000 in 1990 to about 40,000 in 2012) and in the number of academics (from 40,000 to 99,000 in the same period). The unprecedented expansion of the system and the stunning growth in its accessibility and affordability have led to the increase in the share of the labour force with higher education credentials to about the European average (24\% in 2012). As often in the case of large-scale institutional change processes, a large number of expansion-driven gradual and incremental changes led to transformational and consequential changes (Mahoney and Thelen 2010; Streeck and Thelen 2005). University management, organization, governance, funding and the academic profession have been in the eye of the storm for two decades, as elsewhere in Europe (Stensaker, Välimaa, and Sarrico 2012; Kwiek 2012b). Now, when the processes of contraction of the whole system (and of the private sector in particular) are in full swing, a fresh look into the past, linking it to the future, is needed. The paper provides an overview of past changes and links them to current and future system-level policy challenges.

\section{The increasingly disciplinarily divided university: hard and soft academic fields}

The first theme links gradual changes in the academic research productivity in various academic fields in the last two decades to changes in the academic profession in a hugely (until 2005) expanding system. Traditional academic rules and norms in top public universities according to which research was of key importance to the academic enterprise (Altbach 2007) were gradually weakening throughout the 1990s in the 
expansion-related, soft academic fields. As we have shown elsewhere in more detail (Kwiek 2012a), the price of this process in soft (as opposed to hard) fields for top public universities was high, though: it was the prolonged institutional (as well as individual academic) focus on the teaching mission, at the expense of the research mission and with the ensuing low research productivity. In the post-communist expansion period (19892005), prestigious public research universities in Poland became much more teachingoriented, especially in soft disciplines, than could have ever been expected judging from their traditionally elite and Humboldtian character. In the current and future contraction era (2006 and beyond), under declining demographics, and with new legislation in force since 2010-2012 which changed the public research funding architecture, teachingoriented segments of public universities are expected by policy-makers to become much more research intensive. The expansion period has led to internally divided top public universities: there is a powerful gap between highly productive research-oriented faculties and departments in hard fields and teaching-oriented faculties and departments in soft fields, with low research productivity and very low international research visibility.

We view the expansion period of the 1990s and the mid-2000s as the period of the gradual deinstitutionalization of traditional academic rules and norms in public universities, with growing uncertainty about which academic behaviours were legitimate and which were not (Olsen 2010, 128), and what the core of the academic identity in research universities was. The gradual deinstitutionalization of the research mission means that the role of research activities in individual academic lives and institutional academic lives was declining. The deinstitutionalization processes were concentrated mainly in soft academic fields, in particular those which were in high social demand and which provided additional multiple employment opportunities to the academic faculty in the expanding private sector. Conducting research in these fields was widely believed not to matter: it was teaching where the action was. The higher education legislation of March 2011 reinstitutionalizes these temporarily suspended traditional rules and norms. It introduces new governance and funding principles, redefines the academic career ladder and presents new rationale behind public support for both teaching and research. It finally makes full-time multiple employment - so deleterious to research engagement and research productivity - hardly possible as of 1 October 2013. Current government-produced, instrumental views of the university (Olsen 2007; Kwiek 2013b) are intended to bring the research and teaching missions in top public universities back to a healthy balance, much needed in knowledge-driven economies in which academic knowledge production increasingly matters (Bonaccorsi, Daraio, and Simar 2007; Kwiek 2013a).

In what we can term the expansion era (1989-2005) in Poland, there were ever more students in both public and private sectors, and estimated $30-40 \%$ of academics (and about $70-80 \%$ of professors) from the public sector in soft fields held parallel employment in the private sector (see Antonowicz 2012). The rationale was to make use of opportunities when they arise and to be able to maintain middle-class standards of living while university salaries were falling behind the salaries of other professionals. All institutions at that time, including public research universities, became teaching-focused in their soft field departments. The traditional academic rules, norms and codes of behaviour which stressed the role of research for individual career progression and for institutional development were widely questioned by the academic community (more in practice than in theory, though: we stop doing research, and we see what happens, if anything). Prestigious public universities were no longer able to provide proper 
legitimation for an established organizational practice of academic research, and the state was not able to provide more than rudimentary research funding. In institutionalism's terms, social (and especially peer academic) pressures on being involved in research were low, and the 'erosion of institutionalized rules' was caused by a 'declining normative consensus' (Scott 2008; Oliver 1992; Djelic and Quack 2008) about what constituted the core of academic activities in top universities.

The reinstitutionalization of the research mission in universities is linked to a coherent reform programme of 2010-2011, marked by a set of six laws of 2010 reforming the research sector and a new law on higher education of 2011 combined with increasing public (national and European) research expenditures. The decline of the research mission coincided with social and economic instabilities of the transition period in Polish economy in the 1990s, started by 'shock therapies' leading to the market economy, and coincided with the expansion era in higher education. The processes of reinstitutionalization of this mission coincide now with the period of well-established market economy, combined with the political stability achieved through the EU membership, and the demography-driven contraction era in higher education.

We argue that the dramatic growth of private higher education in the 1990s was made possible by the gradual and parallel decline of traditional academic codes of behaviour in public universities (in soft disciplines). Large-scale multiple employment of the academic profession for about a decade became the (academic) norm, not the exception. The price to be paid by the system as a whole was high, though: it was a growing isolation from the international research community. Academics relieved from 'taken-for-granted' (Scott 2008, 196; Djelic and Quack 2008, 301-304) research duties eagerly focused on largescale, profit-driven teaching, both in their institutions and, especially, in the private sector. The suspension period lasted until the last wave of reforms which may be interpreted as a government-inspired (rather than academics-driven) legal call to return to a traditional academic normative consensus about what top public universities should be doing and why.

A simple bibliometric analysis (performed on the basis of the SCImago Journal \& Country Rank data-set developed from the information contained in the Scopus database, and referred to the 1996-2010 period) demonstrates a powerful disciplinary divide in research productivity between hard and soft fields. The three strongest fields throughout the 1996-2010 period studied have been physics and astronomy, mathematics and chemistry (globally ranked 13, 13 and 14 in 2010, with more than $10 \%$ of all US publications in each case). In 1996, these three fields were globally ranked roughly in the same, relatively high positions $(13,15$ and 12 , respectively; and at that time still with less than $10 \%$ of all US publications). The weak fields, in contrast, include arts and humanities, social sciences and economics, econometrics and finance, ranked relatively low in 2010 (34, 39 and 35, respectively). In 1996, two of the three fields - arts and humanities and social sciences - were ranked much higher, though (23 and 24, respectively; the third field was 31). We seek to explain the reasons for these changes in the period of a decade and a half. There are many reasons why, in general, the natural sciences and related fields were able to maintain their relatively high position both in the global and in the regional (Central European) knowledge production in 1996-2010 and why the social sciences and related fields performed, by comparison, much worse. One of them is the individual academic and institutional focus on teaching and the teaching mission, and the individual academic and institutional disregard of the research mission in faculties of arts and humanities, social sciences and economics in most prestigious Polish 
universities, major national knowledge producers. Poland in those fields in which massive expansion occurred has lost significantly its international research visibility. While in the global ranking (all fields), Poland moved gradually down the ladder from rank 16 (1996) to rank 18 (2003) to rank 19 (2010) and rank 20 (2012), its still relatively good position is due mostly to those fields in which academics had virtually no opportunities for multiple employment in the private sector and no opportunities to have excessive fee-based part-time teaching in their own institutions.

From a regional perspective, Polish chemists, physicists, astronomers and mathematicians published more international papers than their colleagues from Slovakia, Hungary and the Czech Republic combined, both in 1996 and in 2010. Their publications accounted for $55.7 \%$ and $54.3 \%$ of all publications from the four countries in respective years. What is important for us here, though, is the cross-country differences in national research outputs in soft, expansion-linked fields. Research output in those fields has been decreasing systematically in Poland, compared with the research output of the three regional competitors. In 1996, in soft areas, the share of Polish research output in the output from the region was relatively high in both arts and humanities $(55.6 \%)$ and social sciences (48.8\%; it was much lower in economics and related areas: 23.8\%). In 2010, though, in the arts and humanities, the number of Polish internationally visible publications was only about half of the number of publications of their colleagues from the Czech Republic and Hungary, and only slightly more than those from Slovakia (Polish publications in the arts and humanities accounted for only about $23 \%$ of all publications from the four countries). In social sciences, the total number of internationally visible publications by Polish, Czech and Hungarian academics was about the same, and in economics and related areas, Polish research output was much lower than the Czech one. But, at the same time, the Polish higher education and research systems are huge by comparison (Poland had more academics than the three other countries combined throughout the 1996-2010 period). The slide in the Polish share of publications in soft academic areas in the region was from $43 \%$ to $26.9 \%$ in the period studied. While academics in smaller systems can be more effective, and more inclined to be open to international research networks, we suggest a different explanation of the Polish research productivity failure: the sustained influence of prevailing academic norms which clearly disregarded the role of research, and especially internationally visible research, for both staying in and being promoted in Polish universities in the period of the deinstitutionalization of the university research mission. As we show elsewhere in more detail (Kwiek 2014; see also Kwiek 2001b), the need for more intense internationalization of Polish higher education is one of the major themes of reforms. In particular, two aspects are focal points in recent policy debates: internationally visible publications as part of 'internationalization at home' and international research cooperation as part of 'internationalization abroad' as the two 'pillars of internationalization' (Knight 2012, 34-37).

Thus, hard academic fields managed to maintain their high positions and soft academic fields noted a downward slide. In particular, the share of Polish publications in arts and humanities and in social sciences in the pool of publications coming from the four regional economies studied slid dramatically from $55.6 \%$ to $18.8 \%$; in social sciences, it slid from $48.8 \%$ to $30.8 \%$. Research productivity across academic areas and across the four regional higher education systems clearly shows that soft areas in Poland were powerfully affected by the processes of the deinstitutionalization of the research mission in universities, given that the level of financial austerity in universities was roughly equal in all academic fields. What is important for the future is that academic 
norms, attitudes and codes of behaviour are changing very slowly, as empirical studies of the academic profession show (Teichler, Arimoto, and Cummings 2013). The current policy challenge is not only to increase the overall low research productivity of Polish academics but also to deal with a cultural and normative divide between hard and soft academic fields produced in the times of educational expansion.

\section{From the expanding privatized to the contracting publicly funded university}

The emergence of the private higher education sector in the 1990s contributed to the demand-absorbing growth - but the expansion occurred throughout the two sectors and throughout the two major modes of studies, full time and part time (Poland has the highest share of part-time students in Europe, 45\%; GUS 2013, 59). The period of expansion in higher education enrolments can be viewed through the double matrix of two major dimensions: public and private sectors, and full-time and part-time modes of studies, or through a single matrix in which the major dimension is fees. The most prestigious first-choice vacancies have been free or tax-based vacancies in the public sector; the second-choice vacancies have been fee-based vacancies in the public sector and vacancies in the private sector.

Polish students can be defined by sectors they come from: public and private. But even more fundamentally, they can be defined as fee-paying and tax-based students. Feepaying students are all students from the private sector (full time and part time) and all part-time students are from the public sector. While according to the former distinction, $27 \%$ of students are enrolled in private institutions and $73 \%$ in public institutions, according to the second distinction, less than half of all students, or $47 \%$, are paying fees (2012). The first impact of a powerful reversed demographic trend is seen through the stagnating, and then falling share of fee-paying students in both sectors (combined) beginning in 2006. The total number of tax-based students have been increasing throughout the last decade, and only in the last four years (2009-2012) the share of tax-based students increased from 44\% (2009) to 53\% in 2012 (GUS 2013, 59). Under declining demographics, the speed of ongoing changes in the student composition by sources of funding (and by sector) is amazing; there is a zero-sum game: public sector gains mean private sector losses.

In the 1990s, when the first private institutions appeared throughout Central and Eastern Europe, Polish higher education policy was focused mostly on educational expansion. Private (called 'non-public') institutions in Poland and elsewhere in the region were mushrooming; there were limited quality assurance mechanisms and accreditation procedures in place at the time. In the two decades between 1990 and 2009, 330 private institutions materialized in Poland, 200 in Western Balkans and about 700 in Central and Eastern Europe. The expansion of the system was closely linked to the economic policy that encouraged external privatization (the emergence of new private providers) and internal privatization (the emergence of fee-based part-time studies in the nominally free, or tax-based, public sector; on the distinction, see Kwiek 2009, 2010). Student numbers in Poland were skyrocketing: the peak of enrolments came in 2005 (1.95 million), and since then every year total enrolments in both public and private sectors were slightly lower, reaching 1.82 million in 2010 and 1.67 million in 2012.

As we have studied elsewhere in more detail (Kwiek 2013b), the expansion was accompanied by hierarchical differentiation: much of the growth was absorbed by public and private second-tier institutions and by first-tier public institutions in their 
academically less demanding and less selective part-time studies. Expansion also took place in specific fields of study, in particular such as social sciences, humanities, economics and law. The expansion was supported by both public and private sources. The inflow of public funding to the public sector in the expansion period was significant but equally significant was the inflow of private funding from fees to both sectors. While the private sector is overwhelmingly reliant on tuition fees, the public sector during the peak of the expansion (especially in 2000-2005) was also heavily reliant on tuition fees from part-timers who were providing $16-20 \%$ of its operating budget.

While the communist-period higher education in 1970-1990 in Poland could be termed unified, following V. Lynn Meek, Leo Goedegebuure and colleagues (Meek et al. 1996) and Yossi Shavit, Richard Arum, and Adam Gamoran (Shavit, Arum, and Gamoran 2007), the recent period of its expansion (1990-2005) showed a transformation from a unified to a diversified system. Higher education under communism was not inclined to encourage expansion, either of existing elite universities or through the formation of new, especially non-university institutions. The number of students in the two decades of 1970-1990 was strictly controlled and, in general, was not increasing. While Western European systems were already experiencing the processes of massification in the 1960s, 1970s and 1980s, higher education in Central Europe was as elitist in 1990 as in the decades past. One of the major reasons of the phenomenal growth of private higher education following the collapse of communism in 1989 in (some) Central European countries, and in Poland in particular, was heavily restricted access to public higher education under communism combined with new private sector employment opportunities. Increasing salaries in the emergent private sector were widely socially recognized, which gradually pushed more young people into higher education.

The processes of (internal and external) privatization are currently in retreat, though: the ongoing changes should be termed 'de-privatization' or 're-publicization' of higher education. Under declining demographics, the number of fee-paying students in the public sector decreased dramatically by almost $40 \%$ in the $2005-2011$ period (GUS 2013, 59 ), as did the share of income from fee-paying students in the public sector, from $16.6 \%$ in 2005 to $11.9 \%$ in 2012 (GUS 2013, 181-184). The private sector has been shrinking dramatically in the $2007-2012$ period, by $30 \%$ (from 660,000 to 459,000 students). The ministerial projections show that the share of private sector enrollments will shrink from $34 \%$ in 2008 to $12 \%$ in 2022 , and the number of institutions may shrink by $80 \%$. The decline of the private sector is fundamental, and cannot be reversed: Poland will witness another decade of its gradual demise, especially that declining demographics is combined with an expanding pool of tax-free vacancies in the public sector. Increasingly (internally and externally) privatized higher education of the expansion period is becoming ever more public, with increasing reliance on public funding. 'De-privatization' replaces 'privatization'.

Thus the dramatically changing demographics becomes the major parameter of higher education policy: enrolments, expected to fall from about 1.95 million students (2005) to about 1.2 million students in 2025, introduce new dilemmas related to public funding, academic selectivity and admission criteria. We expect public policy for higher education in the times of expansion to be fundamentally different from public policy in the times of contraction, as we have explored the issue elsewhere in more detail (Kwiek 2013b). Powerful demographic shifts may thoroughly change the structure of the system and the remonopolization of the system by the public sector cannot be excluded, due to the gradual (spread over the next decade) decline of the private sector. The processes of the 
intersectoral differentiation of the expansion era may be replaced with the processes of the intersectoral de-differentiation (or homogenization) of the contraction era.

A possible policy intervention could be either in the private sector only (public subsidization of teaching in the private sector) or in the public sector only (introducing universal fees in the public sector), or in both sectors (the combination of both policy interventions). But Poland does not seem to be politically prepared for the introduction of universal fees in the public sector and for the introduction of public subsidies in the private sector which might slow down the processes of the gradual disintegration of the private sector in the coming years. Whatever policy choices are made, though, the contraction is going to be a defining feature of the Polish system for at least another decade.

\section{Towards the increasingly stratified university}

While demographics have been fundamentally changing the higher education system, changes in politics have led to comprehensive reforms of both higher education and research systems. Their major part was the 2010 law on a new 'National Research Council' (or the NCN). The rationale behind its establishment was twofold: to leave decisions about research funding for fundamental research to the academic community and to increase the overall competition for research funding (as elsewhere in Europe; Stensaker, Välimaa, and Sarrico 2012). Until the recent wave of reforms, more than a half of research funding was distributed through a (almost non-competitive) 'statutory research' funding. It was allocated to university units based on periodic (institutional rather than individual) research assessment exercises. And for about two decades, it was the major source of research funding. According to the new law, at least $50 \%$ of all research funding will have to be awarded on a competitive basis from 2020 onwards. The $\mathrm{NCN}$ emerges as a major player in this change of research funding regimes: away from non-competitive (and institutional), statutory research funding and towards increasingly competitive (and individual) grant-based research funding. The other new funding agency, the National Centre for Research and Development (or the NCBR), supports applied research and university-business links. The research funding allocated through the NCBR in 2012 was about five times higher than that allocated through the NCN $(4.5$ billion PLN and 900 million PLN, or about 300 million USD and 1.5 billion USD, respectively).

A gradually changing formula for the research funding distribution is leading to the 'haves' increasingly having more competitive research funds and the 'have-nots', increasingly having less, with mechanisms of cumulative advantage (and disadvantage) at work. New funding mechanisms lead to the emergence of two new families of institutions: those strongly and moderately research-oriented on the one hand, and those with no research mission (and no research funding) on the other. During its first two years of operation (2011-2012), the NCN funded over 4000 grants (4360), with budgets totaling roughly a half billion USD. The NCN (focused on fundamental research) is a Polish equivalent of the extremely successful European Research Council that provided 7.5 billion EUR to European academics in the 2007-2013 period for what it terms 'frontier research'. The rationale for creating both agencies (an independent agency, academics making decisions), the division into streams of funding and the structure of disciplinary assessment panels is almost identical. The results of calls for proposals in all categories have been stunning. They reflect a new geography of knowledge production as 
well as the growing stratification of the Polish higher education system. The policy direction for non-research-involved higher education institutions (HEIs) clearly rejects the traditional Humboldtian unity of teaching and research: they should focus exclusively on teaching, especially in professional areas.

Where does the new competitive research funding go? The two largest national universities - the Jagiellonian University in Krakow (UJ) and Warsaw University (UW) are in fierce competition with each other, earning over 400 grants each. These are the only institutions ranked in the 2013 Academic Ranking of World Universities, in the $301-400$ ranks. UJ and UW together received about $20 \%$ of all research grants and of all research funding available from the NCN. The second cluster of universities is University of Poznan (UAM), AGH University of Science and Technology in Krakow, University of Wroclaw and Warsaw University of Technology. The number of their grants is considerably lower, though, with UAM receiving 212 grants and the other three universities receiving 114-145 grants each.

While the research dominance of the two largest universities is clear, what also emerges from the distribution of the NCN grants are national ranking lists: the top 10 institutions have won $42 \%$ of all grants and the top 20 institutions have won $55 \%$ of all grants. The statistics for the most prestigious grants (called Maestro) offered to top-level researchers involved in frontier research follows the same pattern. There were 99 Maestro grants awarded in the period studied and $30 \%$ of them went to UJ and UW, $45 \%$ to the top $5,60 \%$ to the top 10 and $80 \%$ to the top 20 institutions. Slightly more than a half of all 40 Maestro grant recipient institutions, at the other end of the spectrum, received only one Maestro grant. The growing concentration of research funding, talents and opportunities has been clear throughout the last two decades. With new research funding mechanisms and the increasing effect of competition, further stratification of the university sector seems unavoidable and is consistent with developments across Europe (Kwiek 2012c, 2013a).

Who are the institutional losers under a new research funding regime? The list of recipient institutions includes slightly more than a half of all HEIs (only 250 in a system of about 450, including 328 private) and several dozens of research institutes of the Polish Academy of Sciences (PAS). The list of non-recipients thus includes about 200 institutions. The winners are top metropolitan universities while the losers are middlelevel and low-level institutions where knowledge production is only marginally competitive. Among the recipient institutions, there are over 100 institutions (or about $40 \%$ ) that received only $1-3$ grants and 71 institutions (or about $30 \%$ ) that received only 1 grant.

Competitive research seems not to be performed in the private sector at all: there are only two private institutions among the first 100 recipient institutions and among top 200 institutions there are only four of them. There are only two exceptions (which might be termed 'semi-elite' private HEIs), both Warsaw-based University of Social Sciences and the Humanities (SWPS) and the Leon Kozminski Academy, with 29 and 13 grants, respectively (each institution received also one Maestro grant). From the point of view of prestige, the NCN data are disastrous to the whole private sector. They are not surprising, though. The private sector in Poland is almost entirely teachingoriented and, due to its profile, unable to participate in a competition for national (or international) research funding. The issue of research-linked prestige is of marginal importance in the context of declining demographics and systematically falling revenues from fees in the private sector studied in the previous section. The competitive 
funding made available through a new national research council may gradually contribute to the emergence of a new class of Polish research-intensive universities. This category is expected to enter Polish public policy discourse with more intensity, accompanied by an ever-higher concentration of research funding and ever-growing stratification of institutions in the coming years. ${ }^{1}$

\section{Still the Ivory Tower university?}

Finally, we shall explore briefly university governance and organization, and specifically the unfading power of the traditional Ivory Tower ideal in Poland. There are two complementary perspectives to analyse national higher education systems: the macrolevel perspective of national higher education statistics on individual universities and higher education system as a whole and a micro-level perspective of internal perceptions of the academic profession. The second, internal perspective, reveals the state of affairs often hidden behind the data aggregated to the level of the higher education sector or its institutions.

Our empirical evidence comes from about 3700 returned surveys of Polish academics. The European data-set we use was produced in two international research projects focused on the academic profession (CAP: 'Changing Academic Profession' and EUROAC: 'The Academic Profession in Europe'). The data for 11 countries - Austria, Finland, Germany, Ireland, Italy, the Netherlands, Norway, Poland, Portugal, Switzerland and the United Kingdom - were cleaned and weighted in a single European data-set by the University of Kassel team. ${ }^{2}$ The survey questionnaire was sent out to the CAP countries in 2007 and to the EUROAC countries in 2010. Overall, the response rate differed from over $30 \%$ in Norway, Italy and Germany to $20-30 \%$ in the Netherlands, Finland and Ireland to about $15 \%$ in the UK and about $10 \%$ or less in Poland, Austria, Switzerland and Portugal. From a full weighted sample of 17,212 cases across 11 countries, we have analysed only the cases of full-time academics $(13,633)$ and academics working in universities $(10,777)$. We have excluded all part-timers and all academics employed in 'other higher education institutions' ('universities' were defined by national research teams). Consequently, the data here are drawn from about $9000(N=$ 8886) cases. Polish academics analysed are only those employed full-time in 'comprehensive universities' (rather than in so-called universities 'with adjectives' such as universities of economics, of medicine, etc.). The international sample characteristics are given in Table 1 below.

We analyse here four statements directly related to the Ivory Tower ideal (viewed here as the low connectedness of universities to the outside social and economic world (percent 'agreeing'; we refer to percentages of answers 1 and 2 combined, on a five-point Likert scale: from $1=$ strongly agree to $5=$ strongly disagree and from $1=$ very much to $5=$ not at all, depending on the question):

- 'Scholarship includes the application of academic knowledge in real-life settings' (B5/2): Poland, together with Austria, ranks the lowest (59\% agreeing versus the European average of $74 \%$ ).

- 'Faculty in my discipline have a professional obligation to apply their knowledge to problems in society' (B5/8): Poland ranks the lowest (40\% agreeing versus the European average of $57.3 \%$ ). 
Table 1 . Sample characteristics by country.

\begin{tabular}{lccccr}
\hline & $N$ & Universities (\%) & Other (HEIs) (\%) & Full time & Part time \\
\hline Austria & 1492 & 100.0 & 0.0 & 65.8 & 34.2 \\
Finland & 1374 & 76.5 & 23.5 & 82.4 & 17.6 \\
Germany & 1215 & 86.1 & 13.9 & 70.7 & 29.3 \\
Ireland & 1126 & 73.3 & 26.7 & 91.2 & 8.8 \\
Italy & 1711 & 100.0 & 0.0 & 96.9 & 3.1 \\
The Netherlands & 1209 & 34.4 & 65.6 & 56.0 & 44.0 \\
Norway & 986 & 93.3 & 6.7 & 89.7 & 10.3 \\
Poland & 3704 & 48.3 & 51.7 & 98.0 & 2.0 \\
Portugal & 1513 & 40.0 & 60.0 & 90.3 & 9.7 \\
Switzerland & 1414 & 45.6 & 54.4 & 58.5 & 41.5 \\
The UK & 1467 & 40.8 & 59.2 & 86.5 & 13.5 \\
\hline
\end{tabular}

HEIs, higher education institutions.

Note: In Austria and Italy, there was no distinction between 'universities' and 'other higher education institutions' in the sample.

- 'Emphasis of your primary research: applied/practically oriented' (D2/2): Poland ranks the lowest $(45.5 \%$ very much versus the European average of $60.9 \%$ ).

- 'Emphasis of your primary research: commercially oriented/intended for technology transfer' (D2/3): Poland ranks the lowest $(9.8 \%$ very much versus the European average of $15.4 \%$ ).

Polish universities differ substantially from universities in the 10 comparator European countries, as viewed from the micro-level perspective of individual academics; they seem much more isolated from the needs of society and economy. They are closer to the ideal of the Ivory Tower than universities in any other European system studied, based on academics' beliefs (along the same lines, and based on national-level statistics, Poland was criticized in international reports on higher education published in the last few years by both the World Bank and the Organisation for Economic Co-operation and Development). This micro-level picture of the low connectedness with the outside world is complementary to the macro-level picture provided by institutional and national higher education and research and development statistics (through such parameters as total income from the industry, the share of income from the industry in total income, either at the national scale or at the scale of operating budgets of particular institutions). Our paper shows an uncommonly low - compared with other European countries - level of readiness on the part of university academics to professionally connect with the outside world, as demonstrated at the level of academic beliefs and attitudes (Becher and Kogan 1980; Birnbaum 1988).

The emergent conflict between the vision of the university (Olsen 2007; Kwiek 2001a) shared by the Polish academic community (the value-based, autonomy-driven 'community of scholars' model, linked to the Ivory Tower ideal) and the vision shared by the Polish policy-making community (instrumental and externally driven model) is about what Bowen and Schuster $(1986,53)$ term as 'basic values'. Basic values are 'derived from long academic tradition and tend to be conveyed from one generation to the next'. While in Western European systems this conflict between Johan P. Olsen's institutional (the university as a 'rule-governed community of scholars') and instrumental (the university as 
a 'tool' for different groups and purposes) visions has a tradition of several decades, following reforms undertaken since the 1970s, in Poland this value-driven conflict only begins to emerge. The Polish 'professorially-coordinated' system, strongly supporting the Ivory Tower ideal, is expecting to be brought in line through reforms with other European systems, already driven increasingly by instrumental logics at both national and EU levels.

The instrumental model of university organization massively promoted in Polish higher education reforms of 2000-2012 may be gaining influence in the coming years through various state-supported changes in university funding and governance mechanisms. The logic of current reforms dooms both models to be in a powerful conflict, grounded in the incommensurability of traditional academic values and rules shared by the academic profession on the one hand, and values and rules promoted by higher education policymakers and reformers on the other. The political economy of reforms and experiences of other European systems tend to show that, in the coming years, academic values and rules will be gradually gravitating towards the second, instrumental model, promoted in subsequent waves of reforms, and away from the first, institutional model. In this way, Polish universities will move away from the Ivory Tower model and become less isolated from the outside social and economic world. At the same time, its organization and funding mechanisms will become fundamentally transformed, though. Consequently, Polish universities can be expected to be 'in transition' in the coming years to a much higher degree than the Polish academic profession desires, leading to a new wave of value-driven conflicts.

\section{Conclusions}

There are several conclusions to be drawn. First, current changes in governance, management and funding bring Polish reforms in line with an array of reform initiatives taken in the last decade across European countries and linked to the changing state-higher education relationships. Second, the major emergent parameter of higher education policy in the future is demographics: its impact on future public funding, admission and selection criteria in top public institutions, the stratification of the academic profession, its research productivity and its morale, as well as on the overall public-private dynamics which is still underestimated in policy debates and policy strategies. The remonopolization of the system by the tax-based public sector and the gradual decline of the private sector in the coming decade will transform the system beyond recognition. Processes of 'de-privatization' or 're-publicization' will gradually replace recent processes of 'privatization'. Third, powerful systemic changes in university governance and management and changes in funding modes (away from largely evenly distributed institutional research funding and towards an ever more competitive and individualized grants-based funding) will shatter the relative stability of the academic profession. Processes of institutional differentiation will draw ever clearer lines between 'haves' and 'have-nots' in research funding in terms of institutions, departments and research groups. Internationally visible research activities will be conducted in an ever smaller number of institutions and departments, and by an ever smaller number of academics - which will also be the end of the enduring myth of the teaching-research unity in Polish universities. The stratified academic profession will be employed in increasingly stratified institutions with diversified missions; most institutions will be teaching-focused, and some will only be research intensive, based on highly competitive funding. And finally, fourth, after two decades of being fundamentally different due to the communist legacy (i.e. being 'post-communist'), some selected Polish universities, owing to ongoing processes of 
academic stratification, have a chance to become fully blown elements of a European knowledge production landscape, with increasingly similar governance and funding regimes and the similarly research-involved academic profession. The differentiation processes of both institutions and the academic profession, accompanied by the ongoing transition from expanding, privatized university to the contracting publicly funded university, are bound to accelerate and radically change the higher education system. Consequently, we thought we were living in interesting times in Polish universities under post-communist transitions - but the coming decade is bound to be even more interesting (also for higher education researchers).

\section{Acknowledgements}

The author gratefully acknowledges the support of the National Research Council (NCN) through its MAESTRO grant [DEC-2011/02/A/HS6/00183] (2012-2017). The author would like to thank for a number of constructive suggestions given by anonymous reviewers.

\section{Notes}

1. Institutes of the Polish Academy of Sciences are a special case in an emergent stratified academic research production system although their role is being marginalized under the global rankings pressures. Its 4800 researchers employed mostly in Warsaw still produce a significant portion of publications and receive a significant portion of public fundings (especially through EU research grants). In particular, the vital academic role of PAS institutes is visible through the research funding distribution from the NCN. PAS institutes have received $20 \%$ of all research grants in the period studied, and almost one quarter $(23.6 \%)$ of all NCN research funding. In the top 30 institutions (ranked by the NCN research funding received), there were 6 PAS institutes, but in the top 50, there were 15 of them. The five top grant recipients among PAS institutes received 208 grants and more than 100 million PLN (or about 30 million USD). Their future is uncertain, though, and long-lasting discussions about their mergers with universities continue.

2. We have worked on the final data-set dated 17 June 2011, created by René Kooij and Florian Löwenstein from the International Centre of Higher Education and Research (INCHER), Kassel, Germany. The author wishes to thank Ulrich Teichler, the coordinator of the EUROAC project (2009-2012), a part of the European Science Foundation, EUROCORES EuroHESC scheme. The Polish research team also included Dr Dominik Antonowicz.

\section{Notes on contributor}

Professor Marek Kwiek holds a UNESCO Chair in Institutional Research and Higher Education Policy at the University of Poznan, Poland. His recent monograph is Knowledge Production in European Universities: States, Markets, and Academic Entrepreneurialism (2013). His research interests include university governance, academic entrepreneurialism, and the academic profession. He has been a partner in 20 international research projects and he is the director of a large-scale Polish 'Program for International Comparative Research in Higher Education' (2012-2017). He serves as the general editor of a book series 'Higher Education Research and Policy' (Peter Lang).

\section{References}

Altbach, Philip G. 2007. Tradition and Transition: The International Imperative in Higher Education. Rotterdam: Sense Publishers.

Antonowicz, Dominik. 2012. "External Influences and Local Responses. Changes in Polish Higher Education 1990-2005." In National Higher Education Reforms in a European Context, edited by Marek Kwiek and Peter Maassen, 87-110. Frankfurt: Peter Lang.

Becher, Tony, and Maurice Kogan. 1980. Process and Structure in Higher Education. London: Heinemann Educational Books. 
Birnbaum, Robert. 1988. How Colleges Work: The Cybernetics of Academic Organization and Leadership. San Francisco, CA: Jossey-Bass Publishers.

Bonaccorsi, Andrea, Cinzia Daraio, and Léopold Simar. 2007. "Efficiency and Productivity in European Universities: Exploring Trade-offs in the Strategic Profile." In Universities and Strategic Knowledge Creation. Specialization and Performance in Europe, edited by Andrea Bonaccorsi and Cinzia Daraio, 144-207. Cheltenham: Edward Elgar.

Bowen, Howard R., and Jack H. Schuster. 1986. American Professors. A National Resource Imperiled. New York and Oxford: Oxford University Press.

Djelic, Marie-Laure, and Sigrid Quack. 2008. "Institutions and Transnationalization." In The Sage Handbook of Organizational Institutionalism, edited by Royston Greenwood, Christine Oliver, Roy Suddaby, and Kerstin Sahlin, 299-323. London: Sage.

GUS. 2013. Higher Education Institutions and Their Finances in 2012. Warsaw: GUS (Main Statistical Office).

Knight, Jane. 2012. "Concepts, Rationales, and Interpretive Frameworks in the Internationalization of Higher Education." In The SAGE Handbook of International Higher Education, edited by Darla K. Deardorff, Hans de Wit, John D. Heyl, and Tony Adams, 27-42. London: Sage.

Kwiek, Marek. 2001a. "Social and Cultural Dimensions of the Transformation of Higher Education in Central and Eastern Europe." Higher Education in Europe 26 (3): 399-410. doi:10.1080/ 03797720120115979

Kwiek, Marek. 2001b. "The Internationalization and Globalization in Central and East European Higher Education." Society for Research into Higher Education International News 1 (47): 3-5.

Kwiek, Marek. 2009. "The Two Decades of Privatization in Polish Higher Education. Cost-Sharing, Equity and Access." In Financing Access and Equity in Higher Education, edited by Jane Knight, 149-168. Rotterdam: Sense.

Kwiek, Marek. 2010. "Creeping Marketization: Where Polish Private and Public Higher Education Sectors Meet." In Higher Education and the Market, edited by Roger Brown, 135-146. New York: Routledge.

Kwiek, Marek. 2012a. "Changing Higher Education Policies: From the Deinstitutionalization to the Reinstitutionalization of the Research Mission in Polish Universities." Science and Public Policy 39 (5): 641-654. doi:10.1093/scipol/scs042

Kwiek, Marek. 2012b. "The Growing Complexity of the Academic Enterprise in Europe: A Panoramic View." European Journal of Higher Education 2 (2-3): 112-131. doi:10.1080/215 68235.2012.702477

Kwiek, Marek. 2012c. "Universities and Knowledge Production in Central Europe." European Educational Research Journal 11 (1): 111-126. doi:10.2304/eerj.2012.11.1.111

Kwiek, Marek. 2013a. Knowledge Production in European Universities. States, Markets, and Academic Entrepreneurialism. Frankfurt: Peter Lang.

Kwiek, Marek. 2014. "The Internationalization of the Polish Academic Profession. A European Comparative Approach." Zeitschrift fuer Paedagogik 5.

Kwiek, Marek. 2013b. "From System Expansion to System Contraction: Access to Higher Education in Poland." Comparative Education Review 57 (3): 553-576. doi:10.1086/670662

Kwiek, Marek, and Peter Maassen, eds. 2012. National Higher Education Reforms in a European Context. Comparative Reflections on Poland and Norway. Frankfurt: Peter Lang.

Maassen, Peter, and Johan P. Olsen, eds. 2007. University Dynamics and European Integration. Dordrecht: Springer.

Mahoney, James, and Kathleen Thelen, eds. 2010. Explaining Institutional Change. Ambiguity, Agency, and Power. Cambridge: Cambridge University Press.

Meek, Lynn V., Leo Goedegebuure, Osmo Kivinen, and Risto Rinne, eds. 1996. The Mockers and Mocked: Comparative Perspectives on Differentiation, Convergence and Diversity in Higher Education. Oxford: Pergamon/IAU Press.

Oliver, Christine. 1992. "The Antecedents of Deinstitutionalization." Organization Studies 13 (4): 563-588. doi:10.1177/017084069201300403

Olsen, Johan P. 2007. "The Institutional Dynamics of the European University." In University Dynamics and European Integration, edited by Peter Maassen and Johan P. Olsen, 25-54. Dordrecht: Springer.

Olsen, Johan P. 2010. Governing through Institution Building. Institutional Theory and Recent European Experiments in Democratic Organization. Oxford: Oxford University Press. 
Scott, W. Richard. 2008. Institutions and Organizations. Ideas and Interests. 3rd ed. Thousand Oaks, CA: Sage.

Shavit, Yossi, Richard Arum, and Adam Gamoran, eds. 2007. Stratification in Higher Education. A Comparative Study. Stanford: Stanford University Press.

Stensaker, Bjørn, Jussi Välimaa, and Cláudia S. Sarrico, eds. 2012. Managing Reform in Universities. The Dynamics of Culture, Identity and Organizational Change. New York: Palgrave.

Streeck, Wolfgang, and K. Thelen, eds. 2005. Beyond Continuity. Institutional Change in Advanced Political Economies. Oxford: Oxford University Press.

Teichler, Ulrich, Akira Arimoto, and William K. Cummings. 2013. The Changing Academic Profession. Major Findings of a Comparative Survey. Dordrecht: Springer. 